\title{
Real-Time Interactive Telementoring between Ethiopia and the United States
}

\author{
Julia L Kerolus ${ }^{1 *}$, Bilen Korra ${ }^{2}$, Talal Ali Ahmad ${ }^{3}$, Antonio Moukhtafi ${ }^{4}$, Miriam Redleaf ${ }^{5}$ \\ ${ }^{1}$ Clinical Assistant Professor, Department of Otolaryngology-Head and Neck Surgery, University of Illinois at Chicago, USA \\ ${ }^{2}$ Chair ENT, St. Peter's Hospital, Addis Ababa, Ethiopia \\ ${ }^{3}$ Co-founder \& CEO, Proximie, Great Road, Bedford, USA \\ ${ }^{4}$ Antonio Moukhtafi, MCS Technical Support Lead Proximie, Bachoura Beirut, Lebanon, USA \\ ${ }^{5}$ Professor of Otolaryngology, Director of Otology/Neurotology, Department of Otolaryngology-Head and Neck Surgery, University of Illinois at Chicago, USA.
}

*Corresponding author: Julia L Kerolus, Clinical Assistant Professor, Department of Otolaryngology-Head and Neck Surgery, University of Illinois at Chicago, USA.
Received Date: May 21, 2020

Published Date: June 02, 2020

\section{Short Communication}

Ethiopia has few Otolaryngologists, resulting in a shortage of qualified experts to educate the next generation of surgeons. The current model for otologic training of Otolaryngologists in Ethiopia consists of periodic surgical campaigns in which surgeries are clustered into single weeks supervised by foreign experts [1]. Surgical instruction has therefore been limited to short intermittent periods when foreign teachers are available. We therefore embarked on a program to incorporate telementoring [2] as an additional tool for surgical education in Ethiopia.

Telementoring involves two-way audio and video streaming in which the teaching surgeon has the capability to use augmented reality [3] to guide operative trainees during their operations. Proximie @ [4] was our chosen augmented reality platform, because it is HIPAA-compliant and enables healthcare professionals in both countries to view the operative field in real time, converse, and even annotate the surgical image [5].

On May 10, 2019 the first operation with telementoring was performed in Ethiopia to the United States after 18 months of trouble-shooting. Thereafter a regular weekly schedule for monitoring ear surgeries at Mekelle University's Ayder Specialty Hospital was established. We present all the factors which needed to be aligned before this real-time transmission was possible.

\section{The First Patient}

A 21-year-old male presented to the Otolaryngology clinic at Black Lion Hospital of Addis Ababa University with long-standing recurrent right otorrhea and decreased hearing. Otoscopic exam found a holo-tympanic membrane perforation, with a pure tone average of 55 decibels (dB).

\section{Procedure}

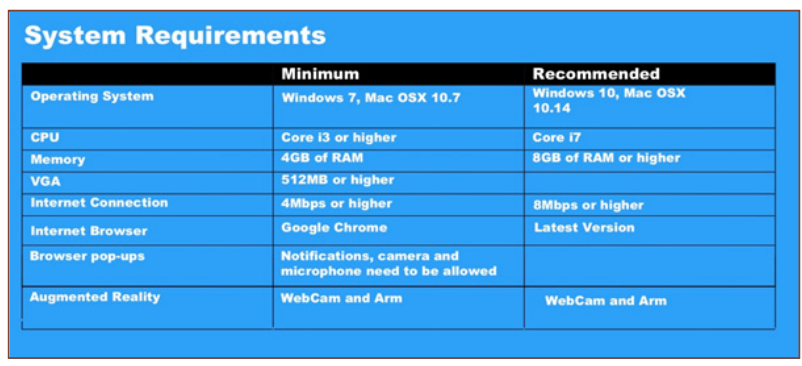

Figure 1: Proximie ${ }^{\circledR}$ platform system requirements: Central processing unit (CPU); gigabyte (GB); random access memory (RAM); video graphics array (VGA); megabyte (MB); megabits per second (Mbps); Web Camera (Web Cam).

The teaching surgeon at the University of Illinois at Chicago (MR) was able to guide the operating surgeon at Addis Ababa University's Black Lion Hospital during key portions of the operation (Figure 
2a). The patient underwent right tympanoplasty with removal of tympanosclerotic plaque and cleaning of the stapes footplate. The incus remnant was then used as an interposition columellar graft from the stapes footplate and to the neotympanum. Video and audio connections were of high quality and maintained throughout the procedure. The teaching surgeon's annotations on the screen were clear to all involved and there was no perceptible time delay.

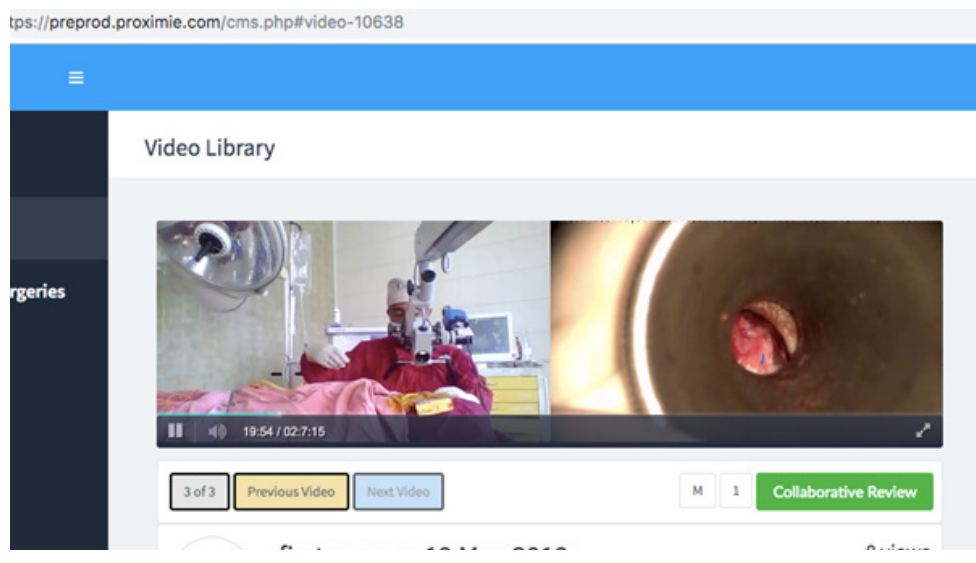

Figure 2a: The remote surgeon's split screen showing the local surgeon (left) and operative field through the microscope (right).

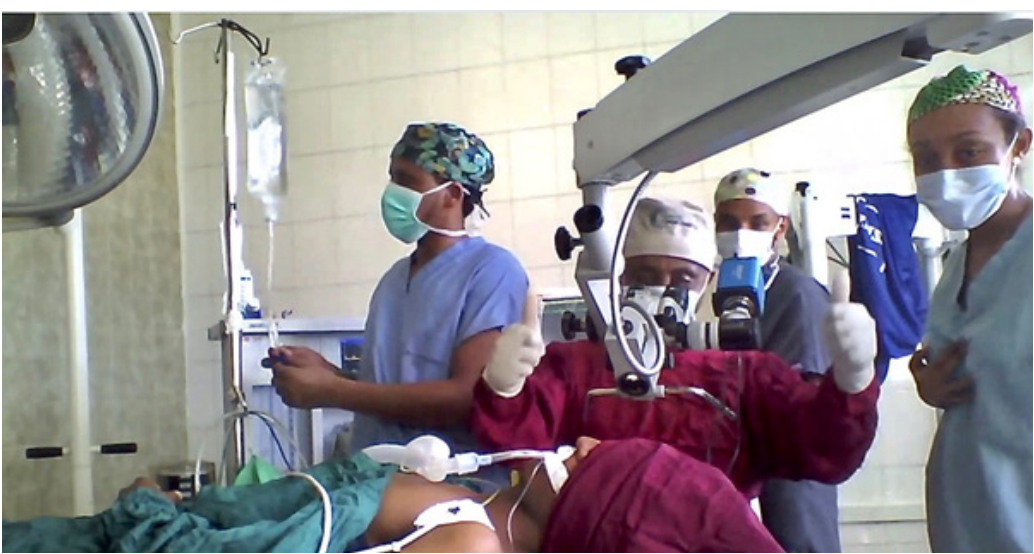

Figure 2b: Ethiopian surgeon gives "thumbs up" to remote surgeon in Chicago once it is confirmed that all is functioning appropriately.

\section{Required Equipment Configuration}

Equipment required for otologic surgery in the primary country include an operating microscope, a beam splitter, a teaching arm with a universal video adaptor, C-mount camera, cable connecting the video out on the camera to the AVIO capture card (HDMI-or S1-compatible), a cable from the AVIO capture card to the laptop's USB port. Internet requirements are 4 megabits per second (Mbps) or higher, with $8 \mathrm{Mbps}$ recommended for optimal communication. (Figure 1) demonstrates the minimum and recommended system requirements for the operative surgeon's laptop/webcam and the teaching surgeon's laptop/webcam. Team viewer® is essential for both laptops for real time trouble-shooting. In this first Ethiopian transmission, there was successful two-way video and audio communication once all connections were achieved (Figure $2 \mathrm{~b}$ ).

\section{Required Personnel}

The operative site in the primary country needs motivated hospital administration, surgeons, hospital staff, and information technology (IT) support personnel-since the many initial obstacles are time-consuming and discouraging. Easy access to the operating room, ability to select appropriate patients, and patient informed consent for broadcast are also essential. For the first few transmission attempts, an IT expert who is conversant with the Proximie® platform should be "on-call" to trouble-shoot on either laptop using Team Viewer.

\section{Discussion}

Many essential features must be in place for successful telementoring. However, the technology is reliable once set-up is complete. It allows surgical trainees to operate under expert supervision, while preserving patient safety and treating patients in a timely manner. Telementoring is an accessible inexpensive modality for surgical education in areas with sparse local expertise.

\section{Acknowledgement}

None. 


\section{Conflict of Interest}

The authors have no conflicts of interest or funding to disclose.

\section{References}

1. Girma B, Bitew A, Kiros N, Redleaf M (2018) High-density otologic camps in regions of sparse expertise. Ann Otol Rhinol Laryngol 127(5): 327-330.

2. Snyderman CH, Gardner PA, Lanisnik B, Ravnik J (2016) Surgical telementoring: a new model for surgical training. Laryngoscope 126(6): $1334-1338$.
3. Khor WS, Baker B, Amin K, Chan A, Patel K, et al. (2016) Augmented and virtual reality in surgery-the digital surgical environment: applications, limitation and legal pitfalls. Ann Transl Med 4(23): 454.

4. Ahmad TA (2014) United States Patent No. US 9,298,884 B1.

5. Greenfield MJ, Luck J, Billingsley ML, Heyer R, Smith OJ, et al. (2018) Demonstration of the effectiveness of augmented reality telesurgery in complex hand reconstruction in Gaza. Plast Reconstr Surg Glob Open 6(3): e1708. 